\title{
On the 85th Birthday of Academician Gurii Ivanovich Marchuk
}

DOI: $10.1134 / \mathrm{S} 0001433810060010$

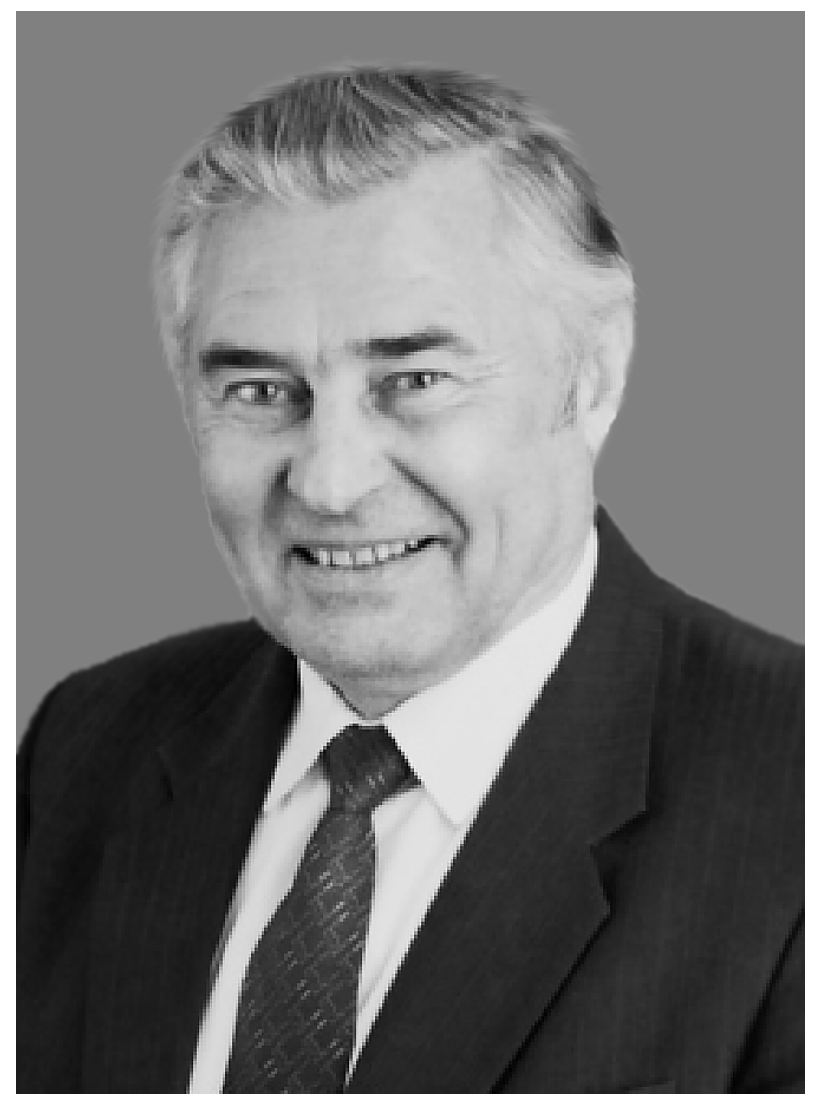

June 8, 2010, marks the 85th birthday of Academician Gurii Ivanovich Marchuk, prominent Russian scientist and great organizer of science. The editorial board of this journal heartily congratulates Gurii Ivanovich on this anniversary and wishes him good health and long years of fruitful and creative activities. 